\title{
Por una Bioética abierta, interdisciplinaria y pluralista
}

Recientemente, la comunidad internacional volcó su atención sobre el caso de Eluana Englaro, la mujer a la que se le practicara la eutanasia en Italia. De noticias como esas están llenos los sitios web, revistas y libros sobre Bioética, y es correcto que sea así. No obstante, la Bioética no se ocupa solamente de situaciones "espectaculares" o que afectan a una minoría. Precisamente, en América Latina se viene construyendo un paradigma de estudios en Bioética que amplía su campo de intereses, señalando la importancia de un conjunto de problemas estructurales en la salud de los pueblos.

La verdad es que sobre la Bioética hace falta mucha más reflexión que involucre a sectores diversos, tanto en la Academia como en la misma sociedad. No siempre los que muestran más interés en la Bioética son los más dispuestos a entablar diálogos abiertos. En El Salvador, hasta hace muy poco, frente a temas como la clonación, el aborto o el uso de anticonceptivos han predominado la 
prédica y las posturas dogmáticas, y hemos carecido de las condiciones para una discusión amplia y abierta a las posturas distintas y a lo que aportan los avances científicos.

Los sectores de pensamiento progresista no solo han preferido mantenerse al margen de estas discusiones - con algunas pocas excepciones-, sino que han considerado que la Bioética es terreno poco apto para reivindicaciones sociales más profundas. El carácter de "minoritarios" que pueden sugerir algunos de los problemas citados, tanto en lo que tienen de "aislados" como en cuanto afectan a un número reducido de personas, se suma a la constatación de que hay otros problemas mucho más urgentes y amplios y que afectan a grandes sectores de la población. Pero mantener esta postura ha sido y sigue siendo un grave error.

Los temas "tradicionales" en Bioética son importantes para todos, ya que involucran situaciones en las que cualquier ser humano podría encontrarse envuelto. Además, que los registros oficiales nos hablen de pocos casos no significa que no haya más o que la problemática no sea más seria. Recordemos también que los abortos ilegales causan muchas más muertes entre las mujeres pobres y que las implicaciones de una política pública errada en lo que respecta a la planificación familiar son mucho más dramáticas entre las familias de escasos recursos y poca educación.

Agreguemos que, desde otra perspectiva, desatender esos problemas resulta inadmisible para el investigador serio. Tanto el científico de la salud, el moralista cristiano o el filósofo preocupado en los criterios éticos que predominan en la práctica clínica deben reconocer la generalidad implícita en aquellos problemas "particulares", ya que involucran aspectos de la humanidad en general. La decisión del padre de Eluana de no suministrar más alimentos a su hija supone una postura clara sobre nuestras posibilidades de manipulación de la vida de las personas, así como sobre lo que entendemos por "vida humana", y son, por lo tanto, disyuntivas extrapolables a muchos otros ámbitos.

Ahora bien, podríamos aventurar que la falta de interés en la Bioética se debe, en parte, a que se la ha limitado a lo que el bioeticista brasileño Volnei Garrafa Ilama "problemas emergentes"; es decir, los que aparecen a medida que las ciencias de la salud realizan nuevos 
descubrimientos y se producen nuevos avances en las tecnologías médicas. Para Garrafa, esto significa dejar de lado todo el ámbito de los "problemas persistentes" - la necesaria erradicación de la fiebre amarilla, la tuberculosis y otros males que aún aquejan a los pobres, que son la mayoría en el mundo-, los cuales no generan demasiado interés en nuestras sociedades, a lo mejor porque no son "de interés" para las grandes compañías farmacéuticas, los medios de comunicación y las políticas de salud de un gran número de países. Casos como el de Eluana son noticia que venden, pero no lo son los miles que mueren en África por las horribles condiciones sanitarias.

¿Deberíamos dedicarnos a los temas de la Bioética? Para responder mejor a esta pregunta hace falta ampliarla, enriquecerla: ¿se ha ocupado la Bioética de lo que debería? Es evidente que el enfoque que proponen especialistas como Garrafa es bastante reciente, pero la Bioética, en general, tampoco es algo muy viejo. Quizá eso sea una ventaja, como es el despertar latinoamericano en torno al tema. Y algo que caracteriza a este despertar es su fuerte énfasis interdisciplinario, como se refleja en los trabajos que publicamos en este número de nuestra revista.

La complejidad de las situaciones exige un abordaje que acerque a filósofos, médicos, teólogos, sociólogos y a todos aquellos que puedan aportar desde su específico ámbito del conocimiento, pero también obliga al investigador clínico a sumergirse en la filosofía o a que el teólogo se documente bien sobre los nuevos descubrimientos en el campo de la genética. No se trata de construir compartimientos estancos, sino de generar un fructífero diálogo entre disciplinas y aún pensar en su misma reconstitución.

Aunque no basta con la interdisciplinariedad, ya que si no se posibilita que los diversos involucrados - alguien diría: "los grupos de interés" - formen parte del esfuerzo de investigación, discusión, prescripción y regulación, el compartir entre disciplinas podría ser fácilmente convertido en un nuevo búnker al que solo tendrían acceso los iluminados. Por eso es que los comités consultivos de Bioética o los comités de ética de la investigación deben estar conformados por una amplia gama de personas que representen a sectores sociales, culturales y de creencias variadas, y no solo por especialistas académicos y científicos. 
Tampoco hay que olvidar que "las ciencias y las filosofías" no están libres de condicionantes culturales o de clase, por lo que debe garantizarse que en los esfuerzos en torno a la Bioética participen representantes de diversas maneras de pensar y las más variadas ideologías. Y en este punto es conveniente ponerse en guardia contra quienes sostienen que representan "una verdad más allá de los cambios históricos y las diferencias culturales" o frente a los que dicen hablar en nombre "del interés común que trasciende las ideologías". Ambas son posiciones claramente ideológicas, precisamente por apelar a cierta neutralidad u objetividad que tiene por objetivo posicionarlas como las únicas capaces de superar las diferencias, cuando lo que realmente pretenden es anularlas mediante su descalificación apriorística.

Como ya señalábamos arriba, este número lo dedicamos a temas propios de la Bioética, la ética de la investigación y diversos aspectos filosóficos, sociológicos y antropológicos relacionados con la salud. Sin pretender ser exhaustivos, consideramos que las entrevistas y artículos dan cuenta de las transformaciones que encontramos actualmente en los departamentos académicos y escuelas de Medicina en diversos puntos de América Latina. Estas transformaciones no serían posibles sin otras que se producen en las sociedades mismas, en los pueblos, cantones y aldeas del continente. El libro Salud y Comunidad en la Otra Latinoamérica, del que publicamos ahora una reseña, nos habla de ello, y nos recuerda que los cambios en nuestras reflexiones y en nuestra manera de pensar sólo aparecen cuando vemos surgir transformaciones concretas en la misma realidad de los pueblos.

Dedicamos este número a nuestro compañero y amigo Fernando Menjívar Suadi (+2009), estudiante de la Licenciatura en Filosofía, quien transcribió las entrevistas que acá publicamos.

Las ilustraciones incluidas en el presente número, salvo las que acompañan el artículo de Perla Castañeda, pertenecientes al artista mexicano Héctor de la Garza, Eko, son una muestra de los estudios anatómicos del artista renacentista Leonardo da Vinci. 